\title{
Factores asociados a la credibilidad y a la autoridad percibidas (o su influencia social) en los medios de noticias online en Colombia
}

\author{
Liliana GuTIÉRREZ COBA \\ Universidad de La Sabana (Colombia) \\ lilianagc@unisabana.edu.co \\ Andrea SAlgado CARDONA \\ Universidad de La Sabana (Colombia) \\ andresasc@unisabana.edu.co \\ Javier Andrés GóMEZ-DíAz \\ Universidad de La Sabana (Colombia) \\ javiergd@unisabana.edu.co
}

Recibido: 5 de diciembre de 2014

Aceptado: 8 de mayo de 2015

\section{Resumen}

Los estudios de medios suelen estar bajo el criterio experto. Esta práctica relega al consumidor de medios a un segundo plano. Este estudio evaluó cualitativa y cuantitativamente la credibilidad y la autoridad percibidas de los consumidores de medios online en el contexto colombiano. Se halló que la credibilidad online es relativamente baja, en comparación con los medios tradicionales, aunque sobresale la reputación y su relación con el medio tradicional. A diferencia de lo que se ha reportado, los consumidores virtuales tienen en cuenta ciertos criterios para valorar la credibilidad de los medios digitales, entre ellos, el aporte del autor de la nota periodística o su experiencia y experticia. Es posible que este, y no el medio en sí, sea el principal influenciador o criterio de autoridad para estos consumidores digitales.

Palabras clave: Calidad informativa, autoridad percibida, medios digitales, consumo de medios.

\section{Factors associated to perceived credibility and authority (or social influence) in online news media in Colombia}

\begin{abstract}
Media studies often are under expert judgment. This practice relegates media consumers to the background. This study evaluated qualitatively and quantitatively perceived credibility and authority from the online media consumers' point of view in Colombia. It was found that online credibility is relatively low compared with traditional media, but reputation excels over its relationship with traditional media. Unlike what has been reported, virtual consumers take into account certain criteria to evaluate digital media credibility, including author's contribution to the news story, as well as his/her experience and expertise. It is possible that him/her, and not the media itself, is the main influencer or authority criteria for these digital consumers.

Keywords: information quality, perceived authority, digital media, media consumption.

\section{Referencia normalizada}

GUTIÉRREZ COBA, Liliana; SALGADO CARDONA, Andrea; y GÓMEZ DÍAZ, Javier Andrés (2015): "Factores asociados a la credibilidad y a la autoridad percibidas (o su influencia social) en los medios de noticias online en Colombia". Estudios sobre el Mensaje Periodístico. Especial noviembre "Periodismo e información de calidad", págs.: 165-180. Madrid, Servicio de Publicaciones de la Universidad Complutense.
\end{abstract}


Sumario: Introducción; 1.1. Internet, un nuevo elemento en la pérdida de credibilidad. 2. Marco teórico. 3. Método. Tipo de estudio; 3.1. Sujetos y diseño; 3.2. Instrumentos. 4. Resultados; 4.1. Grado de credibilidad del medio; 4.2. Factores que determinan la credibilidad del medio; 4.3. El aporte del periodista a la credibilidad; 4.4. La autoridad percibida o influencia del medio en el lector; 4.5. Relaciones entre Autoridad (o Influencia Social) y Credibilidad Percibidas. 5. Discusión y conclusiones. 6. Referencias bibliográficas.

\section{Introducción}

Al hacer un recorrido por la historia del periodismo, es fácil darse cuenta de que la credibilidad de los medios ha estado siempre cuestionada. En el siglo XV, las gacetas, los primeros periódicos que aparecieron en la historia, rápidamente se convirtieron en órganos de difusión de la monarquía (Briggs y Burke, 2002); este vínculo con los intereses de una clase, puso por primera vez en tela de juicio la credibilidad de la información consignada en el papel.

A pesar de estas primeras dificultades, los periódicos continuaron surgiendo con fuerza. Durante la Ilustración, ganaron popularidad por simplificar los géneros que tradicionalmente habían sido de uso exclusivo de los intelectuales. Los periodistas escribían ensayos, informes y reflexiones filosóficas sobre temas de actualidad, pero con la intención de que la información fuera entendida también por el pueblo. Se trató de una democratización del conocimiento que no resultó del agrado de los intelectuales, quienes consideraban que los periodistas, al hacer uso de un lenguaje menos elevado, desacralizaban las ideas. Rousseau, por ejemplo, escribió:

"¿Qué es un libro periódico? Una obra efímera, sin mérito y sin utilidad, cuya lectura, desdeñada y despreciada por las gentes ilustradas, no sirve sino para dar a las mujeres y a los tontos vanidad sin instrucción, y cuya suerte, después de haber brillado por la noche es un tocado, es morir por la noche en el guardarropa" (citado por Aguirre, 1998: 26).

La aparición del liberalismo económico como doctrina, cambió no sólo la historia económica de Occidente sino la percepción que se tenía sobre el periódico, antes enaltecido y ahora tomado como un simple producto comercial. Desde finales del siglo XIX los diarios comenzaron a captar más y más pauta comercial y aunque esto por un lado reafirmó la independencia periodística, creo una nueva subordinación: el periódico se convirtió en una mercancía. La información estaba dirigida a un público específico, el mismo que tenía la capacidad económica para adquirir los productos y servicios anunciados; los medios se autocensuraban ya no sólo para evitarse el ir en contra de los intereses del Estado sino de los pautantes. En aquel momento, el pensador español Luis Ariquistaín escribió sobre el periódico industrial lo siguiente:

En la época moderna un capitalista considera la fundación de un periódico con la misma seriedad y solicitud que la explotación de una mina, el trazado de un ferrocarril, una traída de aguas o de otro negocio cualquiera. Un fabricante de jabón y agua de azahar, por ejemplo, quiere transformar su industria o invertir en otra el capital sobrante. Y se le ocurre fundar un diario. No sabe escribir, pero con su dinero adquirirá plumas que escriban lo que él quiera... No tiene idea alguna es inculto, es trivial, es incapaz de ninguna elevación de espíritu; pero no importa: su función, como capitán de industria, se limita a ofrecer cada día al público lo que el público pide o vagamente 
desea; cumple a la perfección la ley de la oferta y la demanda" (citado por Barrio, 2001: 81)

El siglo XX trajo consigo una racha de guerras, que se convirtieron quizás en los momentos más negros para la credibilidad de la prensa. En A Test of the News", un ensayo de Walter Lippmann y Charles Merz publicado en el New Republic en agosto de 1920, los dos conocidos autores criticaban duramente la calidad de la información que recibía el pueblo americano sobre la revolución Rusa:

"La cobertura de la Revolución Rusa es un absoluto desastre. El resultado final es casi siempre engañoso en las cuestiones esenciales, y una noticia engañosa es peor que ninguna noticia...Cualesquiera que sean las excusas, las disculpas, los atenuantes, permanece el hecho de que no se le pudo garantizar la información mínima necesaria sobre un evento de extraordinaria importancia a un gran pueblo inmerso en una crisis colosal" (citado por McChesney, 2013: 42).

Durante la guerra civil norteamericana Wilbur F. Storey, propietario y editor del Times, mandó esta orden a sus corresponsales: "Telegrafíen todas las noticias que puedan. Cuando no hayan noticias, envíen rumores" (Sohr, 1998: 28).

En España Franco tergiversó la historia a través de la prensa. Cuando Guernica fue bombardeado y los medios en el mundo publicaron la información, de inmediato la prensa oficial creó una realidad alterna en la que los republicanos, "las hordas rojas", fueron responsabilizados del incendio; los nazis crearon su célebre departamento propaganda con el objetivo principal de usar la información para subir la moral de las tropas y desmoralizar al enemigo.

En los años sesenta y setenta, Estados Unidos vivió el amargo episodio de Vietnam mientras la televisión estaba en su apogeo y con el ánimo de competir con ese nuevo medio que parecía iba a quitarle a sus lectores, muchos periódicos publicaron informaciones tan gráficas que fueron cuestionados no por estar representado los intereses de un grupo económico o del Estado, sino por amarillistas.

La Guerra del golfo de 1991, la Guerra de Irak que comenzó en el 2003, por mencionar solo algunos conflictos, fueron otra muestra más de pérdida de credibilidad en los medios, ya que los cubrimientos a nivel mundial estuvieron plagados de imprecisiones y fuertemente controlados por el estado norteamericano, que prácticamente censuraba o manipulaba la información.

\subsection{Internet, un nuevo elemento en la pérdida de credibilidad}

La masificación del uso del internet a mediados de los años noventa, produjo el mayor cambió que hasta el momento ha tenido la prensa: la digitalización de la información.

Para el año de 1999, el número de periódicos online en el mundo era de catorce mil y aunque menos del cincuenta por ciento producía ganancias, los medios impresos continuaban emigrando hacia la red. A comienzos del siglo XXI el número de usuarios de internet continúo creciendo. En mayo del $2001 \mathrm{AOL}$ anunció que tenía veintinueve millones de usuarios, The New York Times anunció que el 57\% de los hogares norteamericanos tenían conexión a Internet y The Wall Street Journal dijo que 461 millones de personas tenían acceso a la red en el mundo (Carlson, 2003: 52). 
Era claro que Internet representaba una oportunidad de negocio y a pesar de que los periódicos en línea no resultaban rentables en el presente inmediato, la realidad demostraba que ser parte de la red, más que en un capricho, se había convertido en una necesidad.

A finales del siglo XX, Jean Baudrillard escribió:

"La meta es la actualización constante de los datos, viva y sufra directamente en la pantalla. Piense en tiempo real; el pensamiento será inmediatamente codificado por el ordenador. Haga la revolución en tiempo real, no en la calle, sino enfrente de la webcam" (Baudrillard 1995: 99).

Esta necesidad de consignar los hechos en tiempo real, conlleva al grave riesgo de cometer imprecisiones. En la era digital, la verificación de la información es casi impensable si se quiere salir con la noticia antes que la competencia, más aún cuando los propios usuarios, antes receptores pasivos, han pasado a convertirse en informadores aficionados, que envían sus propias noticias y fotografías de actualidad por redes sociales o las comparten en sus blogs.

Micó, Canavilhas, Masip y Ruiz (2008) señalan varias causas para la pérdida de credibilidad de los medios en tiempos digitales: la creciente espectacularización de las noticias; la politización de los medios; la multiplicación de algunas prácticas reprobables como el uso abusivo de noticias de agencia, la emisión de imágenes éticamente discutibles o la publicación de noticias falsas (recuérdense las crónicas inventadas de Jayson Blair en The New York Times), manipuladas o con errores evidentes.

Y aunque como las cifras lo señalan ${ }^{1}$, el número de personas que consume noticias por medios digitales aumenta vertiginosamente, esto no está necesariamente relacionado con la credibilidad que tienen sobre lo que los medios les informan ni con la influencia que el medio pueda tener en las decisiones, actitudes y acciones de la sociedad.

De allí precisamente surgen nuestras preguntas de investigación:

¿Cuál es la percepción de credibilidad y autoridad que tienen los consumidores sobre los medios digitales de noticias en Colombia?

¿De qué manera influye la información en las decisiones y comportamientos de los consumidores de noticias online?

\section{Marco teórico}

La credibilidad se entiende como la confianza en el rigor, la verdad y la precisión de la información que publica un medio (Nozato, 2002; Flanagin \& Metzger, 2000; John-

La encuesta realizada en Estados Unidos por el Pew Research Center for the People and the Press, del 1 al 5 de diciembre del 2010, entre 1.500 adultos, indica que cada vez más personas citan Internet en lugar de los periódicos como su principal fuente de noticias (The Pew Research Center for the people and the press, 2011). El más reciente estudio de tendencias Digitales sobre los usos de Internet en Latinoamérica, realizado en 15 países de la región, determinó que el $81 \%$ de las personas lee noticias cuando se conecta a la red (Tendencias Digitales, 2012). 
son \& Kaye, 2000; Schweiger, 2000), y la autoridad percibida como el "poder" implicado o inferido por el consumidor de medios periodísticos que le permite confiar en la información consumida, es decir, la percepción sobre la prensa, por parte de la audiencia, como autoridad creíble sobre la información que, en parte, la hace una institución política bien establecida (Cook, 1998).

Por otra parte, el concepto de credibilidad está asociado al proceso persuasivo (Myers, 2005). En los medios masivos se intenta persuadir a las personas para que tomen ciertas actitudes respecto a diversos temas y respecto a la identidad del medio que se utiliza para la recepción de información. Autores como Pornpitakpan (2004), quien ha revisado el tema de la persuasión y particularmente la credibilidad de la fuente, ha identificado como factores determinantes de la credibilidad a la experticia y a la confiabilidad atribuible al medio. Estos dos factores se han revisado ampliamente en la literatura y han sido tomados como indicadores de credibilidad de la fuente (Flanagin \& Metzger, 2007; Nozato, 2002; Swan, 2004).

Fogg (2003) postuló en su teoría de la prominencia-interpretación, que dos cosas pasan cuando las personas juzga la credibilidad de la información en línea: (1) los usuarios notan algo (prominencia) y (2) los usuarios hacen un juicio sobre eso que notan (interpretación). La prominencia es la probabilidad de que un elemento del sitio de Internet o website sea notado o percibido; si no lo es, no afectará el juicio de credibilidad. La interpretación es el momento en que el usuario evalúa los elementos notados, y además propone tres factores que la afectan: (1) asunciones del usuario (prejuicios, cultura, experiencias pasadas o heurísticos); (2) habilidades/conocimientos; y (3) el contexto del sujeto, las normas de la sociedad en que vive y sus expectativas.

Consecuentemente con la persuasión y las actitudes, la influencia social se sirve de este proceso persuasivo. Según Cialdini y Mortensen (2007), la influencia social define el proceso por el cual se trata de cambiar el comportamiento de las personas para que se ajuste al de otras, y que los medios utilizan para crear determinadas realidades. Este proceso se puede dar de tres maneras: obediencia, conformidad y sumisión.

De estas tres formas de influencia, la conformidad es un indicador de lo que sucede en la mente de los consumidores de información, pues nos dice, que cuando las situaciones son ambiguas, las personas se guían por el comportamiento de otros para tomar decisiones sobre sus acciones, aunque también lo hacen para obtener la aprobación de los demás, ya que lo que se busca es la aprobación de las demás personas y no reflejar en el comportamiento lo que realmente se desea (Cialdini y Mortensen, 2007).

Esto significa que las personas, en relación con la credibilidad de los medios en Internet, elijen como más creíble aquellos medios que son reconocidos por otros como creíbles, es decir, aquellos que por tradición son leídos. Así mismo, Hovland, Janis y Kelley (1953) proponen la teoría de la credibilidad de la fuente, en ella exponen que la gente será persuadida más fácilmente cuando la fuente se presenta como creíble. Esta teoría presenta tres modelos: el factorial, el funcional y el constructivista.

El modelo factorial ayuda a determinar en qué medida se califica la fuente como creíble; el modelo funcional ve la credibilidad como el grado en que la fuente satis- 
face las necesidades individuales del receptor; y el modelo constructivista analiza lo que el receptor hace con la propuesta de la fuente. En esta medida la credibilidad que perciben los receptores de la información difundida por Internet se presentaría en tres componentes: atribución de credibilidad, la satisfacción de necesidades y el uso de la información. Estos autores han sido tomados como referentes para el análisis de los resultados.

\section{Método. Tipo de estudio}

El presente estudio es de corte descriptivo-correlacional, multi-método, ya que se han usado tanto métodos cuantitativos como cualitativos en su recolección y análisis de datos relevantes asociados a la credibilidad de los medios online vigentes en Colombia. Inicialmente se desarrolló y validó un cuestionario cuantitativo con preguntas cerradas en su mayoría (ver más adelante), que luego se complementó con entrevistas semi-estructuradas con el propósito de ampliar algunos asuntos sobre la credibilidad percibida del medio digital frecuentemente consumido.

\subsection{Sujetos y diseño}

Con respecto al método cuantitativo, a partir del envío de 103.650 correos electrónicos durante el mes de septiembre de 2010, y de la publicación de un link de acceso al micrositio de la Facultad de Comunicación de la Universidad de La Sabana, en el que estaba disponible el cuestionario de la encuesta, se logró convocar un total de 344 hombres y mujeres (índice de respuesta $=0.003$ ). En la tabla 1 se describen los diferentes datos socio-demográficos de los participantes.

Tabla 1: Variables socio-demográficas de los participantes. Fuente: Datos del estudio

\begin{tabular}{|l|l|c|c|}
\hline $\begin{array}{c}\text { Variables Socio- } \\
\text { demográficas }\end{array}$ & \multicolumn{1}{|c|}{ Categorías } & Frec. & \% \\
\hline \multirow{4}{*}{ Género } & Femenino & 165 & 48 \\
\cline { 2 - 4 } & Masculino & 179 & 52 \\
\cline { 2 - 4 } & sub-total & 344 & 100 \\
\hline \multirow{4}{*}{ Rangos de Edad } & 18 a 27 años & 156 & 45,2 \\
\cline { 2 - 4 } & 28 a 37 años & 71 & 20,6 \\
\cline { 2 - 4 } & 38 a 47 años & 66 & 19,2 \\
\cline { 2 - 4 } & años o más & 40 & 11,6 \\
\cline { 2 - 4 } & sub-total & $333^{*}$ & 96,7 \\
\hline \multirow{4}{*}{$\begin{array}{l}\text { Grado de } \\
\text { Escolaridad }\end{array}$} & Postgrado & 134 & 38,9 \\
\cline { 2 - 4 } & Pregrado Universitario & 156 & 45,3 \\
\cline { 2 - 4 } & Secundaria & 43 & 12,5 \\
\cline { 2 - 4 } & sub-total & $333^{*}$ & 96,7 \\
\hline
\end{tabular}




\begin{tabular}{|l|l|c|c|}
\hline \multirow{4}{*}{$\begin{array}{l}\text { Estrato } \\
\text { Socioeconómico }\end{array}$} & 2 & 24 & 7,0 \\
\cline { 2 - 4 } & 3 & 102 & 29,6 \\
\cline { 2 - 4 } & 4 & 132 & 38,4 \\
\cline { 2 - 4 } & 5 & 56 & 16,3 \\
\cline { 2 - 4 } & 6 & 30 & 8,7 \\
\cline { 2 - 4 } & sub-total & 344 & 100 \\
\hline *Datos No Reportados & 11 & 3,3 \\
\hline \multicolumn{2}{|l|}{ Total } & $\mathbf{3 4 4}$ & $\mathbf{1 0 0}$ \\
\hline
\end{tabular}

En lo que se refiere al método cualitativo, fueron seleccionadas 20 personas consumidoras de medios por Internet, con quienes se realizaron procedimientos de Autoobservación mediante la técnica de Registro de pensamiento en voz alta (Ericsson \& Simon, 1980, 1993), con el fin de determinar las conductas o comportamientos de los consumidores de información en internet, a través del registro de los comentarios y razones por las cuales navega de una determinada manera por la página. Posteriormente, se realizaba una entrevista semi-estructurada para tratar de precisar algunas de las conductas observadas y/o verbalizadas, y profundizar en otros aspectos relacionados con la selección del medio o medios consultados y la credibilidad que éstos le merecían.

\subsection{Instrumentos}

Para dar respuesta a las preguntas de investigación planteadas, se diseñó un cuestionario con 90 ítems, que permiten, por una parte, evaluar los criterios que tienen en cuenta las personas al momento de elegir las páginas web de noticias que leen, establecer los hábitos de consumo que tienen con respecto a este tipo de páginas; determinar los criterios de calidad informativa que tienen en cuenta y establecer qué tanto creen en la información que les proveen estos medios.

La encuesta fue construida a partir de una exhaustiva revisión de la literatura existente sobre el tema, tomando en consideración los conceptos que han sido identificados como los más relevantes para el estudio del consumo de páginas web, calidad y credibilidad y se basaron en los modelos de preguntas de investigaciones precedentes como las de Flavián y Gurrea $(2007,2008)$ y Hashim y Meloche (2007), entre otras.

Los ítems inicialmente diseñados fueron sometidos a una revisión de expertos y luego fueron piloteados con 40 estudiantes de Comunicación Social de la Universidad de La Sabana para determinar los índices de confiabilidad iniciales y para mejorar el comportamiento de las escalas. A partir de la literatura consultada, se optó por diseñar las preguntas con una escala de calificación tipo Likert de seis puntos.

En este artículo, nos referiremos exclusivamente a las variables relacionadas con la credibilidad y autoridad percibidas de los medios, de manera que describimos las variables utilizadas para estos dos aspectos:

Se diseñaron 18 ítems relacionados para evaluar la credibilidad percibida y autoridad, los cuales se midieron en Escala de Likert, con un escalamiento de 1 a 6 que va 
desde: totalmente en desacuerdo $=1$, hasta totalmente de acuerdo $=6$. El índice de validez de los ítems, según el Alpha de Cronbach, es de 0,72.

En lo que se refiere a la parte cualitativa, la entrevista semi-estructurada contemplaba las siguientes preguntas:

- ¿Tiene algún ritual específico de consulta, una hora un lugar especial en el que le gusta consultar las noticias o no?

- ¿Qué cosas no deben faltar nunca en un sitio web de información noticiosa?

- ¿Qué cosa haría que usted tome la decisión de no volver a consultar el sitio web de su preferencia?

- ¿Qué tan importante es para usted la calidad de la información que ofrece el sitio web?

- ¿En su concepto la calidad informativa es medible? ¿Por qué?

- ¿Qué criterios de calidad informativa son importantes para usted?

- ¿En qué está representada la calidad de la información que recibe?

- ¿Cuál es el medio que más consulta por internet para informarse?

- ¿Por qué consulta ese medio?

- ¿Qué tanto influye en usted, en lo que piensa, decide o hace, la información que recibe a través de ese medio?

- ¿Confía en la información que le brinda este medio y por qué?

En este artículo nos referiremos sólo a aquellas respuestas que se relacionan con la credibilidad y la influencia social del medio.

\section{Resultados}

\subsection{Grado de credibilidad del medio}

Inicialmente se comparó la credibilidad de los medios masivos de comunicación tradicionales y el Internet. Se obtuvo que la prensa es el medio con mayor credibilidad percibida, ya que un 53\% de los encuestados ubicó su credibilidad en los niveles más altos de la escala ( 5 y 6 ). Le siguen la radio, con un $50 \%$ de personas que lo ubican en los rangos de alta credibilidad, la Internet $(36,6 \%)$ y la televisión (23,8\%).

El 46,2\% le confiere poca credibilidad a la información que obtiene de los medios digitales; seguido de un $41,8 \%$ de consultados que le cree medianamente.

"Tomo distancia de lo que leo, en realidad me influye más la conversación que tenga con otras personas que estén informadas. No trago entero porque sé que obviamente los medios de comunicación tienen un interés que se refleja en sus notas. Por ejemplo, el hecho de que en las fotos en ambos medios esté el presidente Santos supremamente afligido ante una casa derrumbada, eso tiene una carga intencional y obviamente y uno tiene que tomar distancia, crearse su propia idea de los respectivos hechos". (Entrevista a mujer, docente, 51 años)

Los participantes en la encuesta suelen basar su forma de juzgar la credibilidad de los medios que consultan en las experiencias que han tenido previamente (43\%), así como en las propias percepciones y opiniones del medio (45,6\%). La primera impresión que se tuvo del medio o el concepto de otras personas tienen sobre el medio son los criterios menos frecuentes para juzgar dicha credibilidad (7,6\% y 3,8\%, respectivamente). 
En este sentido, Tsfati y Cappella (2005) señalan que actualmente más de dos tercios de la población estadounidense piensa que los medios son influenciados por personas y organizaciones poderosas y que las coberturas de noticias son tendenciosas. Como consecuencia, las personas con altas calificaciones de escepticismo mediático reducen su uso de los medios tradicionales de noticias y optan por fuentes alternativas.

\subsection{Factores que determinan la credibilidad del medio}

Para los consultados, hay factores que determinan la percepción de credibilidad de un medio. Por ejemplo, para un $61,4 \%$ de personas resulta importante que el periódico en línea tenga buena reputación, o que esté respaldado por organizaciones expertas en informar $(51,2 \%)$.

Que el medio confirme la información antes de publicarla, es muy importante para el $93 \%$ y que el contenido que se publique sea exacto y fiel a la verdad, es importante para el 91,2\% de las personas, y en un porcentaje igual, resulta que el medio se retracte cuando se equivoque. Si bien la inmediatez es una condición indispensable en el ámbito digital, el costo de no verificar una información puede resultar alto, tanto para el periodista como para el medio:

"Hay muchos indicadores que hablan de la calidad de las noticias: la actualización, la inmediatez, los recursos multimedia. En internet es muy importante la actualización, tener muchos recursos relacionados que le permitan a uno profundizar, que yo pueda tener más información en menos tiempo, pero en ese afán se dan falsos positivos, noticias falsas, que por el afán de salir primero están mal. Eso acaba con la credibilidad". (Hombre, publicista, 28 años)

El $77,1 \%$ de los encuestados califica como muy importante que el medio acuda a fuentes informativas diversas al desarrollar un tema noticioso y que además sean identificables con nombre propio $(82,8 \%)$. A diferencia de una fuente anónima, que despierta cierto nivel de incertidumbre, publicar la identidad de la fuente influye en gran parte en la credibilidad de la noticia.

"Uno nota rápidamente cuando no ha sido bien trabajada la información. Uno lee la nota y dice: este periodista eso lo sacó de un noticiero de televisión y lo está transcribiendo o esta noticia está sesgada porque solamente están preguntando la opinión de uno de los implicados. Uno lo identifica claramente". (Mujer, docente 51 años)

Entre los elementos que permiten a los lectores establecer la credibilidad del medio que están consultando están que en la página web se publique información general de la empresa, tal como los propietarios, los objetivos, la misión, historia, etc., lo cual resulta importante para el $61,1 \%$.

La tradición de quienes son sus propietarios, en términos de reconocimiento social de una familia o grupo empresarial, es un elemento que no puede desconocerse, ya que las repuestas de los consultados estuvieron distribuidas de manera similar: para un $29,9 \%$ resultó un factor de gran importancia, para el 38,9\% de mediana importancia y para el $31,1 \%$, de poca importancia. 
Otros elementos, como por ejemplo la publicidad con que cuenta el sitio, resultan irrelevantes para el 47,4\% y medianamente importantes para el 36,6\%; o específicamente la publicidad relacionada con el tema de la nota periodística es también irrelevante para el $45,6 \%$ y medianamente importante para el 38\%.

El 40,7\% de los consultados está medianamente de acuerdo con que la calidad de la escritura es menor en los medios digitales que en la versión impresa, mientras que el 29,1\% está plenamente de acuerdo con esta afirmación. Este es uno de los factores que hace que los lectores duden de la calidad y credibilidad del medio, como señalaron algunos de los entrevistados:

"No volvería a consultar una página donde no encuentre lo que esté buscando, que el contenido que encuentre no me esté aportando a lo que yo quiero conocer, que haya errores de ortografía, que el contenido sea flojo o insuficiente. Muchas veces he encontrado inconsistencias en la información, es incompleta, no es clara, no es precisa. A veces se nota que la persona que hizo la información la hizo de afán, como que no se dio cuenta de lo que estaba haciendo". (Mujer, abogada, 25 años)

El aumento del número de errores en las versiones digitales de los medios de comunicación ha sido además evidenciado por investigaciones previas. Por ejemplo, Stepp (2009) encuentra que en Estados Unidos el número de noticias en la red con errores de legibilidad va en aumento y señala las consecuencias de estas omisiones, que incluso derivan en disminución de lectores.

Como ya se dijo antes, la satisfacción de necesidades y el uso que la gente le da a la información es otro factor determinante de la credibilidad. En este estudio, el 65,4\% de los encuestados considera importante que las páginas web informativas publiquen contenido que sirva para algo práctico. Para ellos, son importantes aquellas noticias sobre las experiencias y actividades del día a día, las relacionadas con los lugares que frecuentan como su residencia o lugar de trabajo $(79,1 \%)$, o las que tratan temas relacionados con los servicios o eventos $(84,8 \%)$. Un alto porcentaje de lectores considera las secciones especializadas como muy importantes $(43,3 \%)$ y reconoce que las noticias publicadas tienen un impacto significativo en la toma de decisiones personales o profesionales $(52,6 \%)$, comprobando la vigencia de lo expuesto por Lippmann (1922) quien resaltó el poder que tienen los medios informativos para definir el mundo de quienes los consumen.

\subsection{El aporte del periodista a la credibilidad}

El nombre del periodista que firma la nota es uno de los factores más importantes en la percepción de calidad que tienen los consumidores de noticias. Por tal motivo, los hemos analizado en un apartado especial.

Para el 65,4\%, el autor de la nota periodística aporta credibilidad al medio. Los criterios que más valoraron de los autores de noticias fueron su honestidad para reconocer y corregir los errores que cometen $(87,8 \%)$, su imparcialidad al tener en cuenta varios puntos de vista en lo que cubre $(84,6 \%$ ) y su experticia $(86,6 \%)$, definida como la capacidad del hablante de hacer ciertas conclusiones acertadas sobre los hechos reportados (Pornpitakpan, 2004). 
"Un periodista es creíble por la manera como escribe, de forma no ofensiva, no irritante y no vulgar, un mensaje respetuoso y no personalizado sino que consulta distintas fuentes y puntos de vista. No me interesa la opinión de esta persona, así que si veo que está cargado a una de las partes definitivamente la hago a un lado (la noticia) y busco gente más objetiva". (Entrevista mujer, ama de casa, 43 años).

Algunos de los entrevistados que consultamos en esta investigación señalaron que confían en el medio de comunicación que consultan por internet debido al prestigio ganado por el medio y por la trayectoria de sus periodistas:

"Confío porque la mayoría de periodistas (de este medio digital) son generalmente de toda la vida, de renombre. Entonces, cree uno que es un periódico en el cual puede uno confiar". (Entrevista mujer, administradora de empresas, 40 años)

"Uno confía en la casa que hace el periódico, en sus periodistas". (Entrevista mujer, secretaria, 48 años)

El hecho de que el periodista tenga formación profesional resulta en general muy importante para los encuestados. En las escalas de calificación 5 y 6, un 65,1\% de las personas consultadas dijo que la formación del autor en carreras como periodismo o comunicación aportaba en gran medida a la credibilidad del medio, y el 53,8 piensa que la formación profesional en disciplinas diferentes a la Comunicación, es también muy importante.

El 65,4\% de los consultados considera muy importante que el periodista tenga varios años de experiencia en su trabajo, y un 52,6\% valora en gran medida que haya recibido premios o reconocimientos por su actividad periodística.

\subsection{La autoridad percibida o influencia del medio en el lector}

En cuanto a la autoridad percibida o influencia que genera el medio en el lector, el $49,5 \%$ se siente altamente identificado con la línea editorial del medio que más consulta, seguido de un $38,7 \%$ que se identifica medianamente con ésta.

"Creo que si genera influencia. Yo leo el editorial y la opinión de los columnistas que me llaman la atención, y a veces uno toma esas mismas posiciones". (Hombre, ingeniero, 45 años)

Un $44,2 \%$ se siente muy adherido a las propuestas y opiniones del medio y el $41,9 \%$ medianamente adherido. E1 72,1\% dice confiar por lo general en lo que publica el medio y el $72,7 \%$ percibe que el medio que consulta tiene buena reputación comparado con otros.

"Si quiero ir a teatro o a cine y me dan una crítica, eso puede influir en mi decisión. Uno sabe que todo lo que sacan ellos (los medios) es oficialista, pero generalmente sí confía". (Entrevista mujer, economista, 25 años de edad)

"Si influyen, en el sentido de que me certifican que la información que está ahí consignada es veraz, real. Muchas veces yo extracto contenidos que hay en la página para aplicarlos a mi trabajo, por ejemplo los indicadores, ya que yo trabajo en la parte administrativa, por ejemplo el valor del dólar. En la página de Bogotá, por ejemplo me están informando 
del pico y placa (restricción vehicular) y yo lo estoy llevando a mi vida, saber cuándo puedo o no sacar el carro. Confío en lo que me dicen porque la información va en tiempo real, lo que me están diciendo es lo que está pasando y no es sensacionalista. Antes uno veía información que ya había pasado, es muy importante ahora que la puedes ver en tiempo real". (Mujer, secretaria, 37 años)

\subsection{Relaciones entre Autoridad (o Influencia Social) y Credibilidad Percibidas} $\mathrm{Si}$ bien, el promedio de estas variables es relativamente alto (Credibilidad del Medio=4.36; Credibilidad del Autor $=4.98$; Credibilidad Total=4.85; Autoridad=4.63), la correlación entre estas, aunque significativas, resultan bajas (Ver tabla 2).

Tabla 2: Correlaciones entre Credibilidad y Autoridad Percibidas.

\begin{tabular}{|l|c|c|c|c|}
\hline \multicolumn{1}{|c|}{ Variables } & $\begin{array}{c}\text { Autoridad } \\
\text { Percibida }\end{array}$ & $\begin{array}{c}\text { Credibilidad } \\
\text { Total }\end{array}$ & $\begin{array}{c}\text { Credibilidad } \\
\text { Autor }\end{array}$ & $\begin{array}{c}\text { Credibilidad del } \\
\text { Medio }\end{array}$ \\
\hline $\begin{array}{l}\text { Autoridad } \\
\text { Percibida }\end{array}$ & 1 &, $23(* *)$ &, $20(* *)$ &, $17(* *)$ \\
\hline $\begin{array}{l}\text { Credibilidad } \\
\text { Total }\end{array}$ &, $23(* *)$ & 1 &, $92(* *)$ &, $63(* *)$ \\
\hline $\begin{array}{l}\text { Credibilidad } \\
\text { Autor }\end{array}$ &, $20(* *)$ &, $92(* *)$ & 1 &, $28(* *)$ \\
\hline $\begin{array}{l}\text { Credibilidad del } \\
\text { Medio }\end{array}$ &, $17(* *)$ &, $63(* *)$ &, $28(* *)$ & 1 \\
\hline
\end{tabular}

** Correlaciones de Pearson significativas al nivel 0,01 (bilateral).

Es por lo menos interesante que exista una baja correlación entre la credibilidad del medio y la autoridad del mismo $(r=0,17 ; p=0.00)$ teniendo en cuenta que, si se cree en lo que los medios periodísticos en internet publican, estos influirían socialmente a sus lectores en términos de su identificación con el medio mismo o con su línea editorial, por ejemplo. Igualmente, la baja correlación entre la credibilidad del autor y su autoridad percibida $(r=0,2 ; p=0.00)$ sugiere poca influencia social de lo que los periodistas publican. Por el contrario, las correlaciones entre la credibilidad del medio y del autor con la credibilidad total percibidas indican que el autor aporta más a la credibilidad total $(r=0,92 ; p=0.00)$ que la del medio mismo $(r=0,63 ; p=0.00)$. Finalmente, la correlación entre la credibilidad percibida del autor y la del medio resulta baja $(r=0,28 ; p=0.00)$, lo cual supone que no todos los periodistas reciben la misma credibilidad.

\section{Discusión y conclusiones}

Los resultados señalan que los consumidores de información periodística en Internet juzgan la credibilidad de la información noticiosa a partir de sus propias experiencias con los medios, así como en sus propias percepciones y opiniones sobre el medio, lo que resulta contrario con el proceso de influencia social descrito por Cialdini y Mortensen (2007), es decir que estos consumidores no toman en cuenta las opinión de los demás, por lo que no se presenta influencia por conformidad en este caso.

Según los tipos de credibilidad señalados por Fogg (2003), los consumidores de información participantes en este estudio estarían bajo el tipo de credibilidad por experiencia, ya que reportan ésta como lo más importante para juzgar la credibilidad. 
Sin embargo, escogen consultar periódicamente un medio por costumbre o tradición, porque es el medio que han leído o visto en la versión tradicional (impresa o de televisión, por ejemplo), de manera que se confirma lo dicho por Rosenstein y Grant (1997) sobre el autorefuerzo de los hábitos de comportamiento, que lleva al lector a buscar la versión digital del medio que ha consultado desde tiempo atrás en otros formatos y plataformas.

Del mismo modo, existe una relación entre adherencia a una línea editorial y credibilidad. Los consumidores de información son más susceptibles a creer en la información del medio con el que tradicionalmente se sienten identificados.

A pesar de las numerosas herramientas disponibles para la transmisión de la información, la necesidad de las organizaciones de los medios por hacer de las páginas web informativas un negocio comercialmente viable ha afectado la credibilidad y la percepción de los lectores sobre la calidad de la información que reciben.

Con los datos encontrados se evidencia que las variables que son tomadas en cuenta al juzgar la credibilidad son: reputación del autor y del medio, confiabilidad en el mensaje, así como competencia, experticia, confianza, fiabilidad, sesgo del autor. En general, estas variables coinciden con algunas de las propuestas por los diferentes autores revisados en la literatura (Pornpitakpian, 2004; Gaziano y McGrath,1986; O'Keefe, 2002; Moya, 1999).

El lector desconfía de las páginas web en las que encuentra errores de gramática, ortografía y puntuación, en las que evidencia la manipulación de la información por parte del medio o del periodista e incluso cuando la noticia se presenta de manera sensacionalista.

La publicación de datos erróneos e imprecisos en las versiones electrónicas de los medios evidencia no sólo la falta de rigor periodístico en la labor del reportero, que confía en la información de una única fuente sin verificar la información suministrada, sino la falta de presencia de los editores que cumplan a cabalidad su función y demuestran la necesidad de fortalecer el ejercicio periodístico para "[...] buscar informaciones allá donde estén y no tener a los redactores amarrados a sus mesas, a sus teléfonos y al fax, para ver qué cae, cómo hacemos a diario con lo que nos viene de fuera" (De Pablos y Mateos, 2004).

Para el consumidor de información, la inmediatez, la actualización los recursos multimedia son altamente valorados, pero en la medida en que no sacrifiquen la veracidad y la profundidad de la información.

Existe la percepción de que la calidad de la escritura, el manejo de las fuentes y la capacidad de ahondar en la información y mostrarle al lector varias perspectivas es vital y depende en gran medida de la experticia del periodista (Pornpitakpan, 2004), con la que los consumidores de información establecen una relación directa entre el nombre y la trayectoria del periodista dentro de un medio y la credibilidad de la información consumida.

No obstante, las bajas correlaciones encontradas entre la credibilidad y la autoridad percibidas sugieren que los medios periodísticos online deben procurar una mayor coherencia entre su línea editorial, sus propuestas u opiniones, con lo que sus perio- 
distas publican, a fin de incrementar su reputación como medio, y por ende, su credibilidad. Por otra parte, deberían aplicar con mayor rigor sus códigos éticos y de conducta periodística para que la percepción de profesionalismo de sus colaboradores permita incrementar la autoridad o influencia social de los mismos, así como la credibilidad del medio en que publican.

Finalmente, se confirma la vigencia de la teoría propuesta por Hovland, Janis y Kelley (1953), extrapolando los componentes de atribución de credibilidad, la satisfacción de necesidades y el uso de la información, a lo que ocurre con el proceso de percepción de credibilidad de las noticias difundidas por medios digitales, de manera que los medios online deberían estudiar cuales son los temas de interés para el grupo objetivo de sus lectores y proponer temas adicionales a los discutidos en las agendas del día a día, ya que la utilidad y la originalidad de los temas son aspectos muy bien valorados por los usuarios.

\section{Referencias bibliográficas}

AGUIRRE, Jesús María (1998): La estructuración de la identidad profesional del comunicador social en Venezuela. Caracas, Universidad Católica Andrés Bello.

BARRIO, Ángeles (2001): Luis Ariquistain, la revista España y la crisis del Estado liberal. Estudio preliminar. Santander, Servicio de Publicaciones de la Universidad de Cantabria.

BAUDRILLARD, Jean (1995): El crimen perfecto. Barcelona, Anagrama.

BRIGGS, Asa y BURKE, Peter (2002): De Gutenberg al Internet: una historia social de los medios de comunicación. Madrid, Taurus.

CARLSON, David (2003): "The history of online journalism". En KAWAMOTO, Kevin (Ed.): Digital Journalism: emerging media and the changing horizons of journalism. Lamham, MD, Rowman \& Littlefield, pp. 31-55.

CIALDINI, Robert y MORTENSEN, Chad (2008): Social influence. En DAVIS, Stephen y BUSKIST, William (Eds.): 21 st century psychology: A reference handbook. Thousand Oaks, CA, SAGE Publications, pp. 123-134. Doi: 10.4135/9781412956321.n65

COOK, Timothy (1998): Governing with the news: The news media as a political institution. Chicago, University of Chicago Press.

DE PABLOS COELLO, José Manuel y MATEOS, Concepción (2004): Estrategias informativas para acceder a un periodismo de calidad, en prensa y TV. Patologías y tabla de 'medicación' para recuperar la calidad en la prensa. Ámbitos, 11-12, pp. 341-365.

ERICSSON, Karl y SIMON, Herbert (1980): "Verbal Reports as Data". Psychological Review, 87, pp. 215-251. Doi: 10.1037/0033-295X.87.3.215

ERICSSON, Karl y SIMON, Herbert (1993): Protocol analysis: Verbal Reports as Data. Massachusetts, MIT Press. 
FLANAGIN, Andrew y METZGER, Miriam (2000): "Perceptions of Internet information credibility". Journalism and Mass Communication Quarterly, 77: 515-540. DOI: $10.1177 / 107769900007700304$

FLAVIÁN, Carlos y GURREA, Raquel (2007): "Perceived substitutability between digital and physical channels: the case of newspapers". Online Information Review, 31 (6), pp. 793-813. Doi: 10.1108/14684520710841775

FLAVIÁN, Carlos y GURREA, Raquel (2008): "Reading newspapers on the Internet: the influence of web sites' attributes". Internet Research, 18 (1): 26-45. Doi: $10.1108 / 10662240810849577$

FOGG, B. J. (2003): "Prominence-interpretation theory: explaining how people assess credibility online". En CHI'03 extended abstracts on human factors in computing systems. New York, ACM Press, pp. 722-723. Doi: 10.1145/765948.765951

GAZIANO, Cecile y MCGRATH, Kristin (1986): "Measuring the Concept of Credibility". Journalism Quarterly, 63 (3), pp. 451-462. Doi: 10.1177 /107769908606300301

HASHIM, Nor Hazlina y MELOCHE, Joseph (2007): “Australian Online Newspaper: An Exploratory Study on Internet Savvy Users, Using Q-Methodology". Journal of Human Subjectivity, 5 (2): pp. 5-68.

HOVLAND, Carl, JANIS, Irving y KELLEY, Harold (1953): Communication and persuasion. New Haven, CT, Yale University Press.

JOHNSON, Thomas y KAYE, Barbara (2000): "Using is believing: The influence of reliance on the credibility of online political information among politically interested Internet users". Journalism \& Mass Communication Quarterly, 77, pp.: 865879. Doi: 10.1177/107769900007700409

MCCHESNEY, Robert (2013): “Aquello fue ahora, y esto es entonces: Walter Lippmann y la crisis del periodismo". Cuadernos de Información y Comunicación, 18, pp. 39-49. Doi:10.5209/rev_CIYC.2013.v18.41713

MICÓ, Josep Lluís; CANAVILHAS, Joao; MASIP, Pere; y RUIZ, Carles (2008): “La ética en el ejercicio del periodismo: Credibilidad y autorregulación en la era del periodismo en Internet". Estudos em Comunicação, 4, pp. 15-39. Disponible en: http://www.ec.ubi.pt/ec/04/pdf/02-Jose-Lluis-Mico-La-etica-en-el-ejercicio-delperiodismo.pdf

MOYA, Miguel (1999): "Persuasión y cambio de actitudes". En MORALES, Francisco (Coord.): Psicología Social. Madrid, McGraw-Hill.

MYERS, David (2005): Psicología Social. México, McGraw-Hill.

NOZATO, Yoshiko (2002): "Credibility of online newspapers". Documento presentado en Convención Anual de la Association for Education in Journalism and Mass Communication. Washington, DC. Disponible en: http://citeseerx.ist.psu.edu/viewdoc/download?doi=10.1.1.105.6673\&rep=rep1\&type $=$ pdf

O'KEEFE, Daniel (2002): Persuasion: Theory and Research. Thousand Oaks, CA, Sage Publications. 
PORNPITAKPAN, Chanthika (2004): "The persuasiveness of source credibility: A critical review of five decades' evidence". Journal of Applied Social Psychology, 34 (2), pp. 249-281. Doi: 10.1111/j.1559-1816.2004.tb02547.x

ROSENSTEIN, Aviva y GRANT, August (1997): "Reconceptualizing the role of habit: A new model of television audience activity". Journal of Broadcasting \& Electronic Media, 41(3), pp.: 324-344. DOI: 10.1080/08838159709364411

SCHWEIGER, Wolfgang (2000): "Media credibility - experience or image?: A survey on the credibility of the World Wide Web in Germany in comparison to other media". European Journal of Communication, 15(1), pp. 37-59. Doi: $10.1177 / 0267323100015001002$

SWANN, Cody (2004): Web design's effect on perceived credibility of online news stories. [Disertasión doctoral, Universidad de la Florida]. Disponible en: http://ufdcimages.uflib.ufl.edu/UF/E0/00/69/62/00001/swann_c.pdf

SOHR, Raúl (1998): Historia y poder de la prensa. Barcelona, Editorial Andrés Bello.

STEPP, Carl Sessions (2009): “The quality-control quandary". American Journalism Review, 31(2): 42-47. Disponible en : http://www.ajr.org/Article.asp?id=4742

TENDENCIAS DIGITALES (2010, octubre 28): 49,2\% de los latinoamericanos prefiere internet para comunicarse con las marcas. Disponible en: http://www.tendenciasdigitales.com/1010/492-de-los-latinoamericanos-prefiere-internet-para-co municarse-con-las-marcas/

THE PEW RESEARCH CENTER (2011): More Young People Cite Internet than TV: Internet Gains on television as Public's Main News Source. Disponible en: http://onlinepubs.ehclients.com/images/pdf/Internet_Gains_on_TV_as_Primary_News_Source-Pew-Jan-2011.pdf

TSFATI, Yariv y CAPPELLA, Joseph (2005): Why do people watch news they do not trust: need for cognition as a moderator in the association between news media skepticism and exposure. Media Psychology, 7(3), pp. 251-272. Doi: 10.1207/S1532785XMEP0703_2 